\title{
On a mixed Kernel Hilbert-type integral inequality and its operator expressions with norm
}

Qiong Liu ${ }^{1}$

${ }^{1}$ Shaoyang University

May 5, 2020

\begin{abstract}
By using some real analysis techniques, We study the structural characteristics of a multi-parameter Hilbert-type integral inequality with the hybrid kernel, and obtain some equivalent conditions for this inequality. We also consider the operator expression of the equivalent inequalities. The conclusions not only integrates some results of references, but also nds some new Hilbert-type integral inequalities with simple form by choosing suitable parameter values.
\end{abstract}

\section{Hosted file}

liu02.pdf available at https://authorea.com/users/300835/articles/430566-on-a-mixed-kernelhilbert-type-integral-inequality-and-its-operator-expressions-with-norm 